\title{
Competitive and Collaborative Approach Towards a More Effective Education in Computer Science ${ }^{1}$
}

\author{
Tomas Cerny \\ Bozena Mannova \\ Czech Technical University, Czech Republic
}

\begin{abstract}
To provide computer scientists with good materials and interesting topics in a class does not necessarily mean that their education is of a high quality, students need to be motivated and evolve skills needed in a real-life employment. Social skills, teamwork, collaboration and competition are valuable aspects they should know in other to become professionals. This paper presents a study with intention to improve education of computer science students in employment-like environments. The study utilizes experience with competitive and collaborative learning in education and Programming Olympiads. Multiple methodological aspects are applied and discussed with regard to students' evaluation. The results show increased student motivation and interest in the course, which produces larger workload in the class.
\end{abstract}

Keywords: Competitive learning; Collaborative learning; Pace environment; Computer Science Education

\section{Introduction}

Computer science has multiple disciplines where some may change and evolve quite quickly which is the trend of the industry where a five years old computer is seen as an archaic one. The education in the computer science prompts for competition as many programs with different functionality, performance and interface are being built by computer scientists every day. Schools produce a lot of students in the area but not all of them will be recruited as experts, but rather as beginners in various companies. The goal of a teacher is to prepare professionals that can succeed in the employment. It is not only important to train students in the field of technologies, techniques, models and processes, but also to build student's social skills, communication capabilities, competitive nature and the ability to collaborate in a team which is in fact often the case in the employment.

The goal of this paper is to improve education of computer science and to provide students with employment-like environment that will help them with the adaptation towards their future career.

${ }^{1}$ This work was funded through SSME project CTU-131-05-101101 and DD project CTU-13136-05-110702 by the Czech Ministry of Education in frame of the Development Programs. It was also presented at the $9^{\text {th }}$ Hawaii International Conference on Education. 
The traditional education provides a good overview of techniques and technology but does not necessarily focus on the related aspects that are essential for becoming a professional. In this paper we present a study that aims to capture additional aspects in education that supplement students' knowledge and motivate them to learn new things more effectively. The methodology used in this study involves competitive and collaborative learning research results and experiences received from the ACM International Collegiate Programming Contests (ICPC) ${ }^{2}$. Aspects that motivate competition, collaboration, pace environment, individual work, and multiple communication patterns are applied to supplement the education. The evaluation of the study is provided with the feedback of 39 students and the lecturer.

This paper is organized as follows. Section 2 describes the background of computer science, competitive and collaborative learning in the programming Olympiads and previous research in the approach. The approach applied in the study comes in Section 3. Section 4 provides with the feedback and evaluation of the course. Finally Section 5 concludes the paper.

\section{Background}

Computer science has a long history, which might be considered going back in the history as far as to ancient Sumerian and Babylon times where the base tool abacus comes from. Simple rationality behind this tool lies in the lines drawn in sand with pebbles. Similar design is used even in these days at modern machines (Carruccio, 2006). Modern computer science as we build on started in $1936 \mathrm{~s}$ with the Church-Turing thesis where Alan Turing built a powerful computational model called "Turing machine" (Sipser, 2005). Turing machine is an accurate model of general-purpose computer and can do everything that a real computer can do. In addition, this model defined existence of certain problems that cannot be solved by computers and are beyond the theoretical limits of computation. Nowadays computer science spreads over a multiple disciplines such as theoretical computers science, algorithms, design patterns, databases, software engineering and many others. Education in these areas often involves math, graph theories, mathematical logic and statistics. For computer science courses a lecturer often follows a table-driven student evaluation. This often statistically distributes students in groups for grading. Table-driven system works and is proven by time but is this the right education direction in the field of computer science?

Parallel to the institutional education, there exist competitions among schools. In those competitions students compete with each other or in groups and the best results are rewarded. In multiple countries there are Programming Olympiads (Anido \& Menderico, 2007), (British Olympiad, 2011), (Indian Olympiad, 2011) among them the most known is the ACM International Collegiate Programming Contest (ICPC). The ICPC contests are popular among the students and are supported by the Association for Computing Machinery (ACM) that is known for its scientific conferences. In those competitions students build teams and compete with others by solving small algorithmic problems. The team that solves the highest amount of problems with the least time and with the fewest mistakes is the winner. In addition, there are multiple contests annually where teams compete in their regions; the best teams reach to the super regions and the best of

\footnotetext{
${ }^{2}$ Both authors are members of the competition organization since 1994
} 
bests reach to the world finals. These competitions started back in 1977 and the participation has grown to tens of thousands of students from almost 2000 universities. The participation is high even though some universities require fees. The key question is: What motivates students to attend the competition? With no doubt, there is a competition among students and also collaboration within their teams, which involves student-to-student interaction. In addition, the ICPC competition started with its own symposium Collaborative Learning Institute (CLI) (Verdou, Lorenzo, Revilla, \& Regueras, 2010) at the world finals to support the idea. Our goal is to apply similar key factors that motivate students in our computer science courses (Kacer, Mannova, \& Stoklasa, 2010) and compare the results with standard table-driven student evaluation.

Similar approaches were already applied in many disciplines of study. Johnson and Johnson (1994) look at how students interact with each other and with materials. They discuss that often the student-to-student interaction is ignored and the course focus is solely on teacher-student interaction. Authors describe three patterns for student-to-student interaction. The first pattern is a competition about who is the best. Secondly, there is an individual work where students do not need to pay attention at other students. The last pattern consists of team cooperation where the students explore each other's contribution to the goal. From these patterns competitiveness is the key, as also confirmed from the research (Johnson \& Johnson, 1994) in the U.S. This in fact might not apply to other schools as in the Czech Republic where our experiment is made. The competition and cooperation among students will support the overall work, as the individual success benefits the whole team. Authors suggest that "the team cooperation encourage each other to do the assigned work, and learn to work together regardless of ethnic backgrounds or whether they are male or female, bright or struggling, disabled or not". The work focuses on five conditions that support cooperative learning as more productive than competitiveness. These conditions are:

1. Perceived positive interdependence

2. Face-to-face interaction

3. Personal responsibility to achieve the group's goals

4. Use of the relevant interpersonal and small-group skills

5. Group processing of current functioning to improve the group's future effectiveness

Authors suggest keeping the team in a small size as it impacts individual accountability. Role assignment in the team might be beneficial for rather large teams. From the individual perspective it is important to let students to teach one another about what they have learned. This in addition supports student's social skills. Interestingly, the authors conclude that in result of cooperation the students build and maintain stable marriages, families, careers, and friendships.

Davis (1993) suggests that the students learn best when they are actively involved in the process. Also, students who collaborate in a group seem to be more satisfied with their course. The work provides a road map to alternative approaches to the collaborative learning such as peer learning, study groups, team learning, etc. Furthermore, it is recommended that strategies are given to collaborative environment where the focus is on team role assignment.

A recent research study on competitive and collaborative learning in senior secondary schools by Kolawole (2008) investigated the effect of the method on academic performance of the students 
in mathematics. The result showed that cooperative learning strategy was more effective than competitive strategy as well as that males performed significantly better than females in both learning strategies. This study indicated that ethnical and cultural aspects that may play a role in the process should also be considered. This can be seen in the ICPC competitions as well. The competitions have significantly more male contestants than female; in addition, there is a huge community and interest in Asia compared to the interest in Europe or Africa. This means that the applicability of Competitive and Collaborative learning fits better to disciplines where the majority is males. In our region this applies to technical universities and computer science. Furthermore, computer science often deals with problem solving techniques, which are well suited for teambased learning (Michaelson, Knight, \& Fink, 2004).

Attle and Baker (2007) create a team-like cooperation in a competitive business-like environment, which prepares students for professional employment. By structuring learning activities the students are driven to cooperate in teams that compete against one another. The definition of competition and collaboration are given as following (Coakley, 1997):

\section{Competition:}

a social process that occurs when rewards are given to people on the basis of how their performances compare with the performances of others doing the same task or participating in the same event

Cooperation:

a social process through which performance is evaluated and rewarded in terms of the collective achievements of a group of people working together to reach a particular goal

Attle and Baker (2007) discuss the combination of both cooperation and competition approaches with the positive aspects of motivational competition through inter-group competition between collaborative team. Students commit to participation in team cooperation if they are rewarded for that participation (Morgan, 2003). Furthermore, recognition for both individual team member and team itself should be evident because it supports the cooperation (Attle \& Baker, 2007). The competition is evident throughout our society, our lives, and our recorded history. Authors see the benefits to the students whose outcomes often exceed content-driven and application-based objectives that prepare them for their careers. Computer science is an area that matches with its professional expectation to this type of learning. In the next section we describe results from the application in our course.

\section{Experiment}

Our study is constructed based on the experience with ICPC competitions, research on the competitive and collaborative learning and the competitive trends in employment. The course of Architectures of SW Systems at Czech Technical University is an eligible course for the 6th semester of Bachelor degree. There were 56 students initially enrolled in the course, where 39 passed the course. The course consists of optional lectures and mandatory seminar, which is the way almost all the courses at our institution are structured and taught. In the following text each course task is identified by a letter (Task ID), which is used for later references. The lectures 
consisted of a talk on topic of software architectures (Bass, Clements, \& Kazman, 1998) (a); design patterns (Gamma, Helm, Johnson, \& Vlissides, 1995) (b); enterprise design patterns (Fowler, 2002) (c); and documentation (Larman, 2002) which in fact covers content from four textbooks (d). Seminars are divided in even and odd weeks where the students either handed out a small demonstration program on a specific architectural type (e) with documentation (f) or read a large research paper for discussion (g). Every odd week students were given a programming challenge to solve $(\mathrm{h})$ where the first few correct submission were progressively rewarded with points. The requirements were very high for an eligible course.

To apply the collaboration, students built teams of two members and worked together on architectural programs (e), documentation (f), presentation of an enterprise pattern (c) in front of the whole class and programming challenges $(h)$. Students could define their own strategy to work on a task together or share the tasks as individuals. Students were evaluated individually as well during the research paper discussion (g) (in English) and by two tests (i).

Table 1. Score per Assignment

\begin{tabular}{|c|c|c|c|c|}
\hline Task ID & Task & Points per task & Points total & Applicability \\
\hline (c) & $\begin{array}{c}\text { Presentation of an enterprise } \\
\text { pattern }\end{array}$ & $10+10$ & 20 & Team \\
\hline (e) & Architectural programs & $4 \times 2$ & 8 & Team \\
\hline (f) & $\begin{array}{c}\text { Architectural program } \\
\text { documentation }\end{array}$ & $4 \times 3$ & 12 & Team \\
\hline (g) & Paper discussion & $5 \times 1$ & 5 & Individual \\
\hline (h) & Challenges & $7 \times 3$ & 21 & Team \\
\hline (i) & Two tests $(\mathrm{a})(\mathrm{b})(\mathrm{c})(\mathrm{d})(\mathrm{g})$ & $20+20$ & 40 & Individual \\
\hline
\end{tabular}

Grading supported a competition in the course. The final grade was assigned by the best score and distributed equally based on the result of others. The course points were assigned in the manner as shown in Table 1. Student could receive up to 45 points as an individual and up to 61 points as a team. Teams had multiple tasks (c), (e), (f), (h) so they received an immediate feedback on their cooperation. In addition the presentations (c) were graded by 10 point from the audience and 10 points from the teacher, so there existed also a communication and feedback from other teams; thus students were directly involved in the education process (Davis, 1993). Programming challenges provided pace environment, and student solving the problem gained points to the team (Attle \& Baker, 2007). Furthermore, challenge winners were honorably announced every first upcoming lecture. According to Johnson and Johnson (1994) the task (h) and final grading provided the competition. The individual work was applied by (g) and (i). Team cooperation was supported by tasks (c), (e), (f) and (h). The team size was kept small (Johnson \& Johnson, 1994) and the team points were applied to all team members, thus they were rewarded for the team participation (Morgan, 2003).

\section{Experiment Evaluation}

Our previous experience with the same course at Charles University with a table-driven evaluation shown that students were not interested much in the course and only a subset of topics was 
applied: (a),(c),(d) and a project. The application of competitive and collaborative approach brought more motivation to the course and allowed to extend the content of the course. The course with a lot of tasks and additional challenges made students feel a pace environment which they face in real employment. We mentioned earlier that students participated in the education process (Davis, 1993) in form of patterns presentations. In our institution it is common that only a small group of students attend the lectures. In here it was about 35 students attending every lecture, they seemed interested in the student presentations, their feedback, and point evaluation of the other teams. Second of all, the results of challenges were announced at lectures.

Students had to collaborate in the team (Attle \& Baker, 2007) in order to receive more points than other teams. Often students split their tasks and solved them individually such as one did implementation part and one did documentation based on the lectures (Michaelson, Knight, \& Fink, 2004). If one team member in this case failed then both received a low score. On the other hand, good results were rewarded with maximum score. Multiple tasks allowed them to receive an immediate feedback for the team so that they could improve in the next task. We believe that it is good to apply rather small projects with a soon feedback rather than a large project with the feedback at the end of the course. Many students had a problem with research papers as English is their second language. On the other hand, they often felt that after the first paper the rest was much simpler. Students had a chance to improve their English and lose the initial fear to talk.

From the perspective of our course all three patterns of communication we applied (Johnson \& Johnson, 1994). At first, students were collaborating in teams and evolving social skills, planning and collective strategies. Secondly, teams were competing in order to receive good grades and do better than others. Thirdly, they had individual responsibilities in the readings and tests.

From the lecturer's perspective, the students were positively motivated by the announcement of the challenge winners in the lecture and also by the applause for their presentation. The student involvement in the grading process seemed to motivate them to attend lectures and learn multiple disciplines that might have been learned in a passive way, such as the team work, planning and to educate other.

Evaluation forms were passed at the end of the course to provide a feedback on individual tasks and course specifics. All students that passed the class filled out the evaluation form. Students that canceled or failed the class (3) did not filled out the anonymous evaluation and they did not appear in the final graphs (Figures 1 to 10). The final grades of the course are shown in Figure 1. Based on the forms, we draw graphs in the following figures - Figure 2 and Figure 3 show student feedback on teamwork and competition. It can be seen that not all students liked teamwork, as sometimes they did not cooperate well in the team. Students with a better final grade preferred competition but those that receive lower grade might have been unhappy about their result. The evaluation of course tasks from Table 1 are shown in Figures 4 to 8. From those we see that teamwork was accepted better than individual work. Figure 9 and Figure 10 show the attendance in the lecture and in the seminar, which was in fact great success for the lecture. 


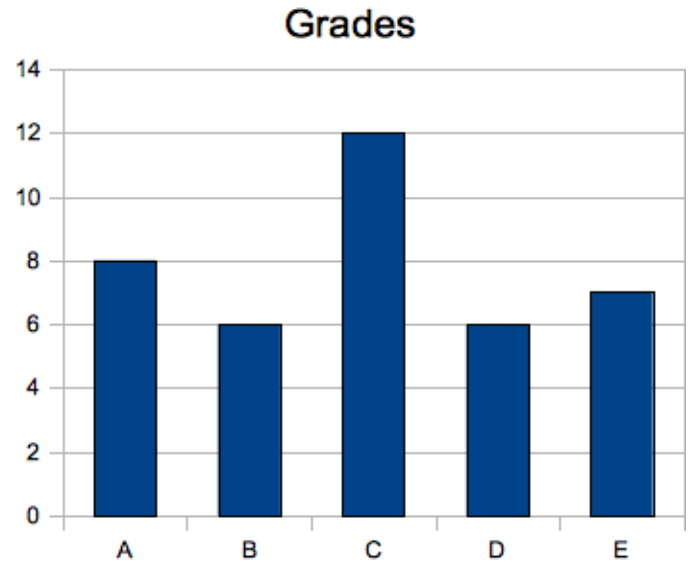

Figure 1. Grade distribution in the course

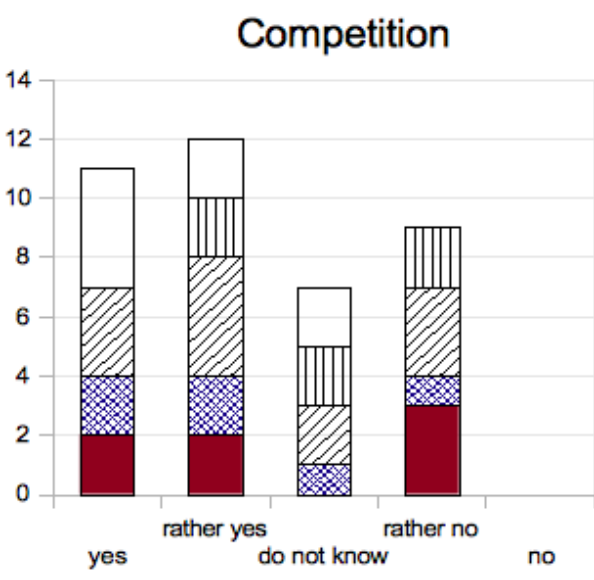

Figure 2. Popularity of competition

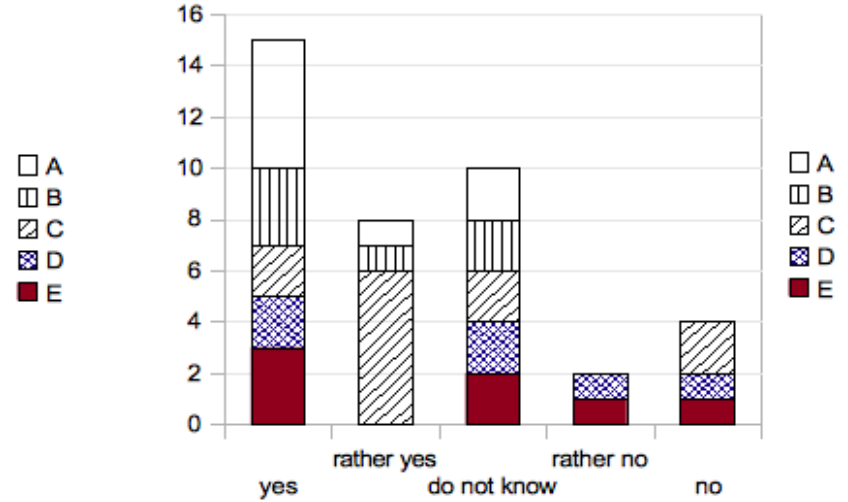

Figure 3. Popularity of team work

\section{(h) Challenge}

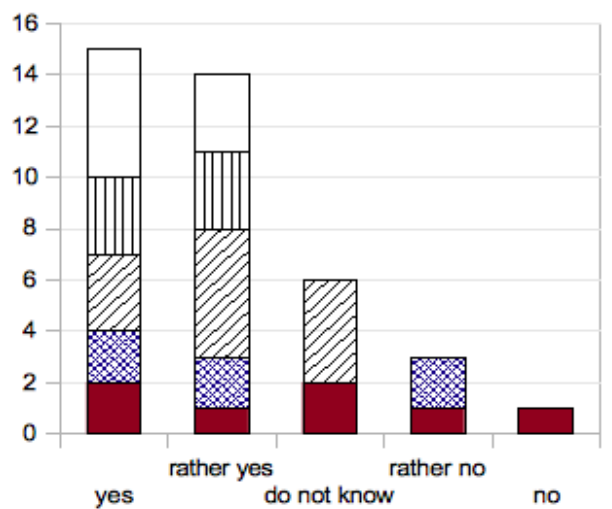

Figure 4. Popularity of challenges $\square \mathrm{A}$
MB
घ C
⿴囗十
$\square \mathrm{E}$

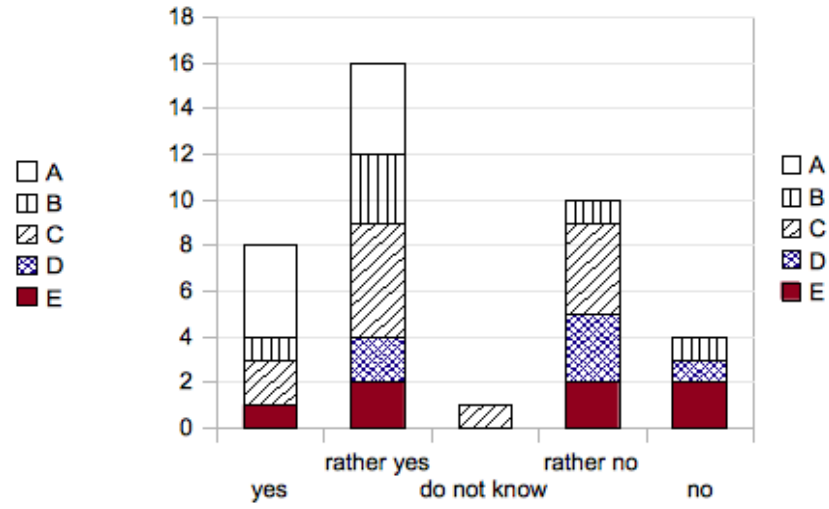

Figure 5. Popularity of research papers 
(e) (f) Projects

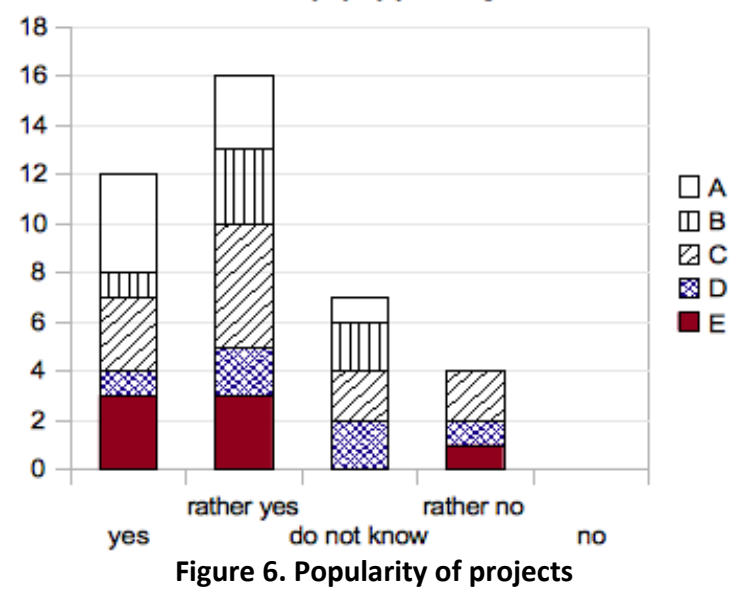

(c) Prezentation

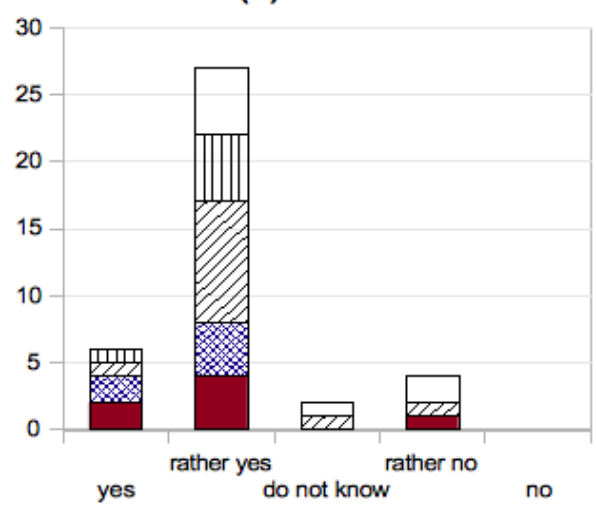

Figure 7. Popularity of presentations (i) Test

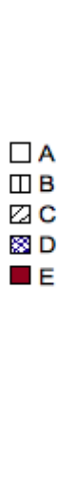

$\square \mathrm{A}$

因C

$\square \mathrm{E}$

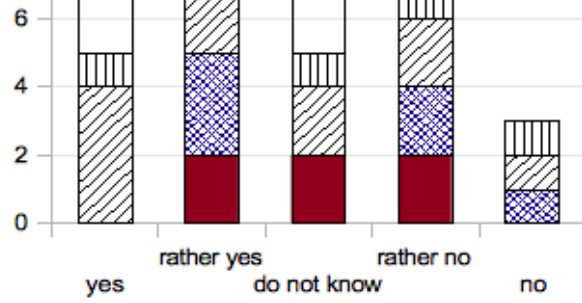

Figure 8. Popularity of tests $\square \mathrm{A}$

पB

$\forall \mathrm{C}$

图 D

$\square \mathrm{E}$
Attendance practices

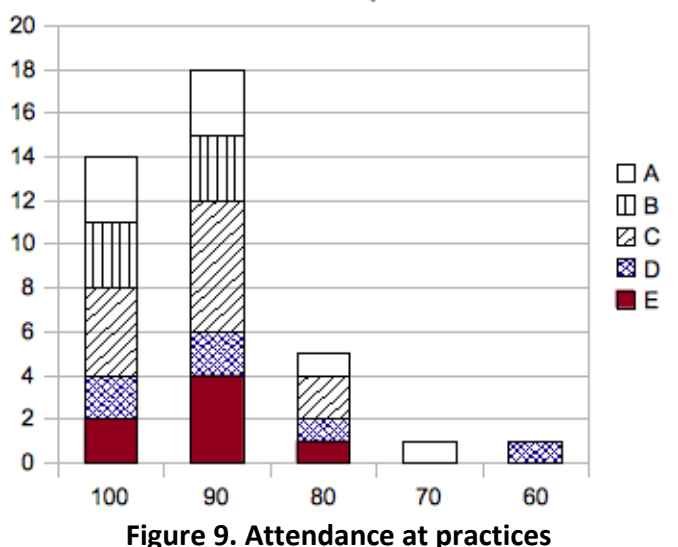

Attendance lectures

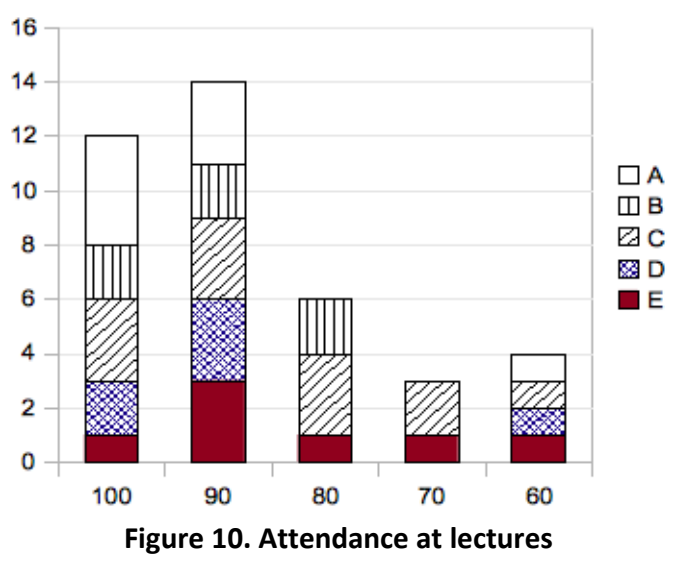




\section{Conclusion}

This paper describes a study that applies competitive and collaborative learning known from programming Olympiads and other research. We have defined multiple tasks for students that were supported by this methodology to stimulate their interest and motivation in addition to standard individual tasks. Furthermore, students were involved actively in the education process (Davis, 1993), and had an experience with pace environment. The course was evaluated based on anonymous student feedback via evaluation forms that were filled by all the students who passed the course.

The majority of students liked to have a competition for the grades and to work in teams. The most of $A$ and $B$ students liked the teamwork and the most of $A$ students also liked the competition. Very popular among students seemed to be small programming challenges, which directly supported competition, pace environment and team interdependence (Attle \& Baker, 2007; Morgan, 2003). A presentation where students influenced the education of others (Davis, 1993) was rather well accepted. Student projects showed to be positive as they played a role for both team cooperation and competition. Furthermore, it confirms that problem solving is well suited for group work (Michaelson, Knight, \& Fink, 2004). Tests and research papers had more balanced feedback in which we rather see a success because not many students like to do tests and read papers in foreign language. The success for research paper section would be higher if the content would impact the practical part of the course.

The great success seen in this study is the attendance at lectures, which was optional. In this course the participation almost matches the seminar attendance. This has something to do with student presentations and their opportunity to influence the points of the presenter (Davis, 1993) and also with the expectation for the challenge Honorable Mention. We believe that both competitive and collaborative learning experiences in education, as we present in the study, had a positive effect to the course.

Among the most beneficial elements, it showed to be very important to involve students in the teaching process as it connects them together and makes them to ask each other on how things work. Furthermore, to allow student to grade the others stimulates their attendance and interest. It is good to provide students with required tasks but bonus task will support them with extra points that impact the overall grade. This way the students can handle extra load. The approach with challenges also supports competition, pace environment and team interdependence as the challenge solved by a team member credits the whole team. It is important to note that there are some students who do not really like this as they like to plan everything at the beginning of the semester.

In the future work we plan to elaborate this study and use its strong parts but also influence the team cooperation. As the next attribute to support real-life concept we plan to apply a scheme where "dollars" would be applied rather than points for the tasks. Those dollars would be deposited to a bank account of each individual. In order to receive dollars, students would be given possible tasks, each rewarded with a certain amount of dollars. It is up to the team planning strategy to finish the tasks. To simulate the pace or perhaps debt environment, each team would be deduced a certain well-defined amount of dollars every month so that their balance would stay 
low. In general, low balance as seen in economy motivates to work harder. If a team does not have enough dollars the bank may provide them with a debt, which must be paid off the following month with some interest. This schema puts constant pressure on teams; it forces them to plan well in order to do well. Furthermore, they would always be motivated to work, as there is the chance to go in debt and bankruptcy.

\section{References}

ACM International Collegiate Programming Contest (2011). Competition for computer scientists. http://cm.baylor.edu/

Anido, R. O. \& Menderico, R. M. (2007). Brazilian Olympiad in Informatics. Olympiads in Informatics (Vol. 1, pp. 5-14). Vilnius: Institute of Mathematics and Informatics.

Association for Computing Machinery (ACM) (2011). http://acm.org/

Attle, S. \& Baker, B. (2007). Cooperative learning in a competitive environment: Classroom international. Journal of Teaching and Learning in Higher Education Applications, 19(1), 7783.

Bass, L., Clements, P., \& Kazman, R. (1998). Software architecture in practice. Boston, MA: Addison-Wesley.

Carruccio, E. (2006). Mathematics and logic in history and in contemporary thought. Piscataway, NJ: Aldine Transaction.

Coakley, J. J. (1997). Sport in society: Issues and controversies (6th ed.). Irwin, CA: McGraw-Hill.

Collaborative Learning Institute (CLI). (2011). http://cm.baylor.edu/ICPCWiki/Wiki.jsp?page= CLI\%20Schedule\%20version\%201

Fowler, M. (2002). Patterns of enterprise application architecture. Boston, MA: Addison-Wesley.

Gamma, E., Helm, R., Johnson, R., \& Vlissides, J. M. (1995). Design patterns: Elements of reusable object-oriented software. Boston, MA: Addison-Wesley.

Davis, B. G. (1993). Tools for Teaching. San Francisco, Jossey-Bass. http://teaching.berkeley.edu/ bgd/collaborative.html

Indian Computing Olympiad. (2011). http://www.iarcs.org.in/inoi/

Johnson, D.W. \& Johnson R.T. (1994). An overview of cooperative learning. In J.Thousand, A. Villa, \& A. Nevin (Eds), Creativity and collaborative learning: A practical guide to empowering students and teachers (pp.31-43). Baltimore, MD: Paul H. Brookes.

Kacer, M., Mannova, B., \& Stoklasa, J. (2010). Rationalization and objectification of programming teaching. In E. Verdou, R. M. Lorenzo, M. A. Revilla, \& L. M. Regueras, L. M. (Eds.). A new learning paradigm: Competition supported by technology (pp.235-250). Madrid: Sello.

Kolawole, E. B. (2008). Effects of competitive and cooperative learning strategies on academic Performance of Nigerian students in mathematics. Educational Research and Review, 3(1), 33-037. 
Larman, C. (2004). Applying UML and patterns: An introduction to object-oriented analysis and design and iterative development (3rd ed.). Upper Saddle River, NJ: Prentice Hall.

Michaelson, L. K., Arletta B. K., \& Fink, L. D. (Eds.). (2004). Team-based learning: A transformative use of small groups in college teaching. Stirling, VA: Stylus.

Morgan, B. (2003). Cooperative learning in higher education: Undergraduate student reflections on group examinations for group grades. College Student Journal, 37(1), 40-50.

Sipser, M. (2005). Introduction to the theory of computation, (2nd ed.). Stamford, CT: Thomson.

The British Informatics Olympiad. (2011). http://www.olympiad.org.uk/

Verdou, E., Lorenzo, R. M., Revilla, M. A., \& Regueras,L. M. (Eds.) (2010). A new learning paradigm: Competition supported by technology. Madrid: Sello.

Correspondence: Tomas Cerny, Department of Computer Science and Engineering, Czech Technical University in Prague, Charles Square 13, 12135 Prague 2, CZ. 